3. John Fielden Consultancy. Supporting expansion: a report on human resource management in academic libraries for the Joint Funding Councils' Libraries Review Group, Bristol: The Councils, 1993.

4. Geleijnse, H. Human and organizational aspects of library automation. In: H Geleijnse \& C Crootaers, eds. Developing the library of the future: the Tilburg experience.

Tilburg University Press, 1994.

\title{
Academic library services for students with disabilities (Research project for the Daphne Clark Award 1991/2)
}

\author{
HAZEL CLARKE \\ Computing Library and Media Services \\ University of North London
}

\section{Introduction}

The project began as a challenge. The University of North London has a goal to facilitate access to all potential students with the academic ability to complete their chosen course. The library plays a key role in providing learning support, yet had no policy on providing for students with disabilities. The research project was formulated, and submitted to LIRG for consideration for the Daphne Clark award 1991/92. Unfortunately, work was interrupted by illness, and then by job changes, and so was delayed for a year. The project was completed in early 1994, although the work itself continues.

\section{Aims of project}

The main objective was to gain information on which to base a policy and plan of action to provide services for students with disabilities. Students at North London provided a practical base for the project.

\section{Methodology}

The project plan consisted of:

- a literature survey and research to gain information about various disabilities;

- visits to organizations, and practitioners - I am indebted to Peter Brophy at University of Central Lancashire for an invitation to spend a day with staff at their excellent centre; (the opportunity to see at first hand the wide range of equipment and to talk to the staff about the provision of services was invaluable);

- $\quad$ research into finding the library users' own solutions - a case study focused on dyslexia support as a microcosm of disabilities in general;

- a questionnaire was devised and a pilot survey conducted;

- $\quad$ equipment was discussed with suppliers and users. 


\section{Results}

a) Disability and higher education in context - government statistics

There are no exact figures on the number of students with disabilities in higher education:

- national statistics on the number of people with disabilities in the overall population are not collected systematically

- not all people wish to declare disability, preferring to preserve their independence.

In education,

- the small section on UCAS forms for students to declare a disability has not until recently been collated statistically

- some students chose not to declare their disability, fearing discrimination.

The Office of Population Censuses and Surveys conducted a sampling survey in 1988. They measured the degree of severity from one to 10, ranging from slight (eg an adult with partial deafness which limited the ability to participate in normal conversations in a quiet room), to severe (eg an adult after a severe stroke, with no locomotion, needing assistance with all functions, no ability to grip or hold items, or to raise arms, with difficulties in communicating and reading).

Their final estimate was that there were likely to be just over 6 million adults with one or more disabilities, and that almost $14 \%$ of adults in private households have at least one disability.

The overall rate of disability rises with age. Of the 20-29 age group, $2.9 \%$ have some form of disability. This rises to $4.2 \%$ at 30-39 years,s rising steeply after age 70 to $40 \%$. At any age, people may have more than one disability.

If university populations mirror the community generally, one could deduce that at least $3 \%$ of the student population in higher education may be expected to have some form of disability. The survey would need to check this figure.

\section{b) Understanding disability}

Acknowledgement is made of the help and advice given by the RNIB library, Philippa Lane, formerly librarian of the Disabled Living Foundation, SKILL, the National Bureau for Students with Disabilities and for the opportunities to attend conferences and exhibitions.

Definitions of disability are produced by the World Health Organization: International Classification of Impairments, Disabilities and Handicaps, and by SKILL which advises the format 'people with disabilities' in preference to other forms such as 'disabled persons'.

The commonly used symbol for indicating disability is a wheelchair, However, this encourages a misperception encountered frequently while conducting the survey. Questions on accessibility for students with disabilities were answered in the first instance by information about physical access to the building via ramps or lifts. Librarians excused their lack of services by explaining 
that people with disabilities could not access the library. A seminar where library staff were invited to list barriers which might prevent students utilizing stock and study facilities also elicited the list of problems for mobility impaired users below. In society as a whole, impaired mobility only accounts for $22 \%$ of the disabled population and of these, only $7 \%$ use wheelchairs.

A checklist was produced of some of the main barriers to access. On the positive side, addressing some of these issues will also assist many other users.

\section{Mobility}

Lack of parking at building

Buildings only reached by steps, with the library on upper floor with no lift

Heavy doors

High counter

Height and lack of space between shelves

No toilet for disabled users

Physical health and stamina

Weight of books

Loan periods

Distractions of noise and movement

Using equipment

Visual impairment

Poor lighting

Most of material in printed form

Small print

No facilities for guide dogs

Finding items in catalogue and on shelves

Deaf and hard of hearing students

Asking for help at counter

Using videos and cassettes

Understanding complex vocabulary or grammar

Following library induction tours and information seminars

Awareness of audible information systems - alarms and public address announcements

Using the telephone to renew books or request information

\section{Language and speech difficulties}

Asking for help at counter

Renewing books by telephone 


\section{Case study: dyslexia support in the library}

Dyslexia, or Specific Learning Difficulty, like disability in general, has a variety of symptoms and effects, not all of which will affect every person. In its most severe form, it can be inhibiting, isolating and debilitating, demanding enormous effort to achieve what may be perceived by others as relatively little result. Specific forms may affect written or spoken language, communication and pattern recognition.

At meetings with the Dyslexia Study group, led by Ellen Morgan at North London, discussion focused on trying to agree solutions to problems. A list of these (in large print) was circulated to the students for comment. They included:

- an identified member of staff in each site library

- $\quad$ general staff training in recognizing difficulties expressed by the group

- $\quad$ provision of group study rooms or screened areas of seating in quiet areas

- flexible loan periods

- $\quad$ reading lists/texts provided in advance with library shelf marks appended

- $\quad$ induction sessions at a suitable pace and including sequence from shelf to shelf, and a clear explanation of catalogues

- $\quad$ OPAC catalogue equipped with a small printer

- $\quad$ arrangements for giving receipts for photocopies

- clear guiding

- $\quad$ equipment including CCTV, Kurzweil reader, and large print software

\section{c) Survey of academic institutions}

The aims were to identify how initiatives are started and funded, and to survey services to students, particularly low cost initiatives.

A telephone survey ensured a high percentage result. A brief pilot survey of a few libraries chosen at random indicated that more insight would be gained into the relationship between institutional and library provision, and the very individual nature of services offered.

Of the 115 libraries identified, information was obtained from $86(75 \%)$

Sector

Selected HE colleges

New universities (COPOL)

Universities (SCONUL)

Total
Contacted

19

42

54

115
Replies

15

33

38

86
$\%$ of total surveyed

$79 \%$

$79 \%$

$70 \%$

$75 \%$

The full telephone survey was begun in March 1992 and was completed in February 1993. 


\section{Results}

\section{Q1 Written policy}

Libraries were asked whether they had a written policy for providing services to disabled students, and if there was an overall policy for the university/college.

\begin{tabular}{|c|c|c|c|c|}
\hline Sector & Replies & $\begin{array}{c}\text { Institutional } \\
\text { policy }\end{array}$ & $\%$ & $\begin{array}{c}\text { Library } \\
\text { policy }\end{array}$ \\
\hline HE Colleges & 15 & 3 & $20 \%$ & 1 \\
\hline New universities & 33 & 14 & $42 \%$ & 6 \\
\hline Universities & 38 & 13 & $32 \%$ & 8 \\
\hline Total & 86 & 30 & $35 \%$ & 15 \\
\hline
\end{tabular}

Most statements formed part of other documents. There was little correlation between library and institutional policies. Of the 15 library policies, eight had been prepared with no institutional framework. Library policy documents, and included leaflets for students outlining the services, staff instruction manuals, and internal memoranda.

\section{Q2 Coordination of services}

Institutionally responsibility for disabled students tended to be combined with other functions

$\begin{array}{lccccc}\text { Sector } & \text { Replies } & \begin{array}{c}\text { Institutional } \\ \text { Staff }\end{array} & \% & \text { Library } \\ \text { HE Colleges } & & 6 & 40 \% & \text { Staff } & \% \\ \text { New universities } & 15 & 16 & 48 \% & 3 & 20 \% \\ \text { Universities } & 33 & 23 & 61 \% & 15 & 45 \% \\ \text { Total } & 38 & 45 & 52 \% & 18 & 48 \% \\ & 86 & & & 36 & 42 \%\end{array}$

In the library it was mainly the Readers Services staff who act as a liaison point for the institution, for assessing students' needs, and for ensuring that library staff are aware of services to be offered. One designated library assistant had been given her own office to ensure confidentiality. She recommended an answerphone to ensure that messages were received.

The value of having a named coordinator to drive the service, in libraries and in their parent institutions, is demonstrated by the strong correlation between the presence of a coordinator and the creation of policy documents, identification of budgets, the acquisition of equipment and the development of services.

\section{Library services}

Policy

Budget

Proactive service

Owning 2 or more major items of equipment
With coordinator

11

3

11

12

\section{Without}

4

0

0 


\section{Q3 Specialist unit}

This is still quite rare, only two new universities and three universities having an identified unit with specialist staff. Where this existed it tended to fall within the library area.

\section{Q4 Funding}

Few academic institutions [13] or libraries [2] had an annual budget reserved for the needs of students with disabilities. In one institution - a former polytechnic - it was a policy issue to topslice $1 \%$ of the institutional non-staff budget for this purpose.

$\mathbf{5 7 \%}$ of libraries responded that they were able to bid to other budgets. Alternative sources mentioned by some libraries included: charitable trusts, friends' fund raising and donations from alumni and others

[Note: from 1993 HEFCE has awarded funds for 'Special Initiatives to Encourage Widening Participation' and this included grants to libraries.]

\section{Q5 Access to library facilities}

Many HE college respondents had a first or second floor library with no lift, while former polytechnics reported fewest problems. Many of the old universities rely on staff assistance although this reduces independence. It is difficult to make a dignified entry out of a goods lift!

Twenty-five libraries provided access to toilets for disabled people.

\section{Q6 Equipment}

Libraries were asked to list equipment, and specifically the following major items

CCTV

HE Collegẹs New universities Universities 9

Total 113

13

Kurzweil or similar

$0 \quad 10$

$10 \quad 8$

8

[Scanner, with character recognition software and a speech synthesizer]
$\mathrm{PC} /$ scanner
0

[includes enlarged text, output via a voice synthesizer or to a Braille embosser, spell checking accessories and software, special keyboards and voice recognition software].

\section{Q7 Services}

To set the context, libraries were asked whether they considered themselves to be proactive, signified by library staff playing an active role in identifying students and making services explicit, formal notification of registered students, a service coordinator and availability of printed leaflets and instructions; 
or reactive, signified by the following: library staff respond to needs when asked for help; there may be a section in the library guide to this effect; services are agreed individually as requested; all staff are involved, but responses may vary.

\section{HE Colleges New universities Universities Total}

$\begin{array}{lll}13 & 32 & 32\end{array}$

Services most commonly available were:

\section{HE Colleges New universities Universities Total}

$\begin{array}{lcccc}\text { Library guide } & 0 & 2 & 5 & 7 \\ \text { Bookable study space } & 1 & 4 & 15 & 20 \\ \text { Reserved desks } & 4 & 9 & 15 & 28 \\ \text { Fetching books } & 11 & 19 & 35 & 65 \\ \text { Making copies } & 11 & 15 & 23 & 49 \\ \text { Concessionary loans } & 2 & 10 & 15 & 27\end{array}$

[eg longer loan periods, increased allowance, library card for helper, telephone renewals, and reduced or waived fines.]

A written guide is extremely helpful, publicizing services to those who might not be aware that they can receive help. It also serves to remind library and teaching staff of the services which the library has agreed to provide. All guides should be clearly printed, black on white, with lots of white space in a minimum 12 point type font.

Other services included individual library inductions to meet and discover any individual needs and suitable responses. Special equipment could be demonstrated.

\section{Alternative text formats}

For students with a visual impairment, there were a number of library solutions including:

- liaising with the RNIB's library and transcription services to arrange texts in large print, Braille, on cassettes on computer disks

- initiating an in-house reading or recording service using students and local volunteers

- providing equipment

For deaf and hard of hearing people,

- $\quad$ subtitles or signing may be added to videotapes

- $\quad$ signing skills training for staff 
- adoption of points from the RNID's Louder than words charter, which includes awareness training for staff, visual provision of information, ensuring a quiet, well-lit environment, and installation of appropriate equipment such as induction loops and visual warning systems.

\section{Conclusions and recommendations}

\section{a) Accessibility}

Libraries were not able to state numbers of disabled students, but guessed that they were probably less than $1 \%$ of the total, indicating that higher education did not appear to be accessible for many students with disabilities. Where services have been initiated to meet the needs of individual students, there is evidence that these have attracted further students, enabling the institution to develop excellent standards of care. These need to be publicized internally and externally.

\section{b) Coordination}

The survey demonstrated that the existence of a coordinator both institutionally and in the library to liaise and communicate is a driving force in facilitating and in developing services. Admissions staff should be aware of learning support facilities. A visit to the site library is recommended for any prospective student with special needs so that they may make their own judgement of whether they are able to use the facilities provided. This would ensure that library staff gain an opportunity to prepare furniture, equipment and texts in a suitable format before the start of term.

\section{c) Policy}

The library should discuss needs with a forum of its disabled users to ensure that the services which it intends to offer are the most appropriate. Policy may then be formulated and should be widely disseminated to ensure that all staff are aware of what is to be offered.

Services should be introduced with the aim of allowing users to achieve independence. A careful balance has to be achieved between this and over-providing to the extent of positive discrimination. and appearing to be patronizing.

\section{d) Staff awareness and training}

All staff should be offered training including:

- regular information on services to be offered;

- $\quad$ instruction in the use and maintenance of special equipment;

- $\quad$ awareness training - particularly meeting students with disabilities;

- $\quad$ sensitivity to terminology.

The LA has a Medical Health and Welfare Libraries Group. There is also an occasional course called The accessible librarian which has a very useful information pack. Disabled Living Foundation, RNID and RNIB offer awareness training courses, and signing courses are also available. 


\section{Computing developments}

It has been one of the intentions of this project to discover in particular low-cost solutions and thus to encourage every library to consider that they might offer appropriate services. However, it is perhaps through computer developments that the biggest impact will be made in the next few years. A few of the possible applications were listed in Section 6 of the survey results above. There has been rapid growth in the amount of material which is available electronically, and thus is suitable for adapted output to speech synthesizers, large print or display and Braille. Even more important perhaps, progress in networking and remote access will help to bring the university and its library to the student, rather than requiring the student to come to the university.

\section{Footnote}

After the presentation of the main results of the survey at the Annual General Meeting of LIRG, it was suggested during the resulting discussion that it may be appropriate to develop an electronic bulletin board for librarians to exchange ideas on improving access for users with disabilities. This project is now underway and a mailing list is being set up.

This report summarizes the main points only of the project. The full text may be requested from the author.

\section{Project EARL (Electronic Access to Resources in Libraries)}

\section{PETER SMITH}

\section{LASER}

Public libraries are facing significant challenges over the next decade and into the 21 st century, brought about by the reexamination of the role of public libraries in society; government legislation; the increasing demand for information and knowledge; the raised expectations of users; the on-going information explosion and the need to offer coordinated, cooperative, economic and efficient services.

The need for public libraries therefore to network their services is now increasingly becoming the focus of attention, and LASER, in conjunction with Public Library Network Awareness Steering Group, UK Office for Library Networking and interested public libraries, has contributed to and facilitated the debate on the need for a networking strategy for public libraries.

Recognizing the increasing requirement for provision of information services by public libraries, LASER organized a workshop sponsored by UNIPALM/PIPEX in Cambridge in May 1994, on public libraries, networking and the Internet. Some 40 senior librarians from public libraries and key institutions across the UK attended.

One of the proposals outlined at the workshop led to the setting up of Project EARL. Project EARL will examine the services, technical infrastructure, and application/communication software required to network public library information and resources services. It will also produce a networking strategy with associated costs for providing public libraries with access to the Internet. 